Article

\title{
Surface Treatment of Bacterial Cellulose in Mild, Eco-Friendly Conditions
}

\author{
Adriana Nicoleta Frone ${ }^{1}$, Denis Mihaela Panaitescu ${ }^{1, *(1)}$, Ioana Chiulan ${ }^{1}$, \\ Cristian Andi Nicolae ${ }^{1}$, Angela Casarica ${ }^{2}$, Augusta Raluca Gabor ${ }^{1}$, Roxana Trusca ${ }^{3}$, \\ Celina Maria Damian ${ }^{4}$, Violeta Purcar ${ }^{1}$, Elvira Alexandrescu ${ }^{1}$ and Paul Octavian Stanescu ${ }^{4}$ \\ 1 Polymer Department, National Institute for Research and Development in Chemistry and Petrochemistry, \\ 202 Splaiul Independentei, 060021 Bucharest, Romania; ciucu_adriana@yahoo.com (A.N.F.); \\ ioana.chiulan@icechim-rezultate.ro (I.C.); cristian.nicolae@icechim-pd.ro (C.A.N.); \\ ralucagabor@yahoo.com (A.R.G.); violetapurcar@yahoo.com (V.P.); \\ elvira.alexandrescu@icechim-pd.ro (E.A.) \\ 2 National Institute for Chemical-Pharmaceutical Research and Development, 112 Calea Vitan, \\ 031299 Bucharest, Romania; angelasasarica@yahoo.com \\ 3 Science and Engineering of Oxide Materials and Nanomaterials, University Politehnica of Bucharest, \\ 1-7 Gh. Polizu Street, 011061 Bucharest, Romania; truscaroxana@yahoo.com \\ 4 Advanced Polymers Materials Group, Politehnica University of Bucharest, 1-7 Polizu Street, 011061 \\ Bucharest, Romania; celina.damian@upb.ro (C.M.D.); paul.stanescu@upb.ro (P.O.S.) \\ * Correspondence: panaitescu@icechim.ro; Tel.: +402-1316-3068
}

Received: 22 May 2018; Accepted: 11 June 2018; Published: 14 June 2018

\begin{abstract}
Bacterial cellulose (BC) with increased hydrophobicity is required for several applications including packaging. Surface functionalization of BC may provide good resistance to moisture, increased barrier properties or improved compatibility to polymer matrices. For this purpose, chemical grafting of $\mathrm{BC}$ in mild, eco-friendly conditions was carried out using different agents. BC membranes were surface functionalized with vinyl-triethoxy silane (VS) or 3-aminopropyl triethoxysilane (APS), by acylation and acrylation. The efficiency of the surface treatments was highlighted by Fourier transform infrared spectroscopy and X-ray photoelectron spectroscopy, by contact angle measurements and by dynamic mechanical analysis. The morphological investigation by atomic force microscopy and scanning electron microscopy revealed an increased compactness for surface functionalized BC, which correlated well with the different increase of the contact angle. BC treated with APS and VS showed more than a twofold increase in contact angle value. Similarly, the crystallinity degree was reduced to $69.6 \%$ and $72.9 \%$ after APS and VS treatments as compared with $84.1 \%$ for untreated $\mathrm{BC}$, confirming the grafting reaction and the decrease in hydrogen bonding. All the applied treatments delayed the degradation of $\mathrm{BC}$. However, the highest increase in thermal stability was observed for silanes treated membranes. Effective, eco-friendly methods for improving the surface hydrophobicity of bacterial cellulose for food packaging were proposed in this study.
\end{abstract}

Keywords: bacterial cellulose; surface treatment; XPS; AFM; silane; SEM

\section{Introduction}

Bacterial cellulose (BC), a 3D network of very strong nanofibers, has been extensively studied for biomedical applications [1-4]. Due to its special properties, i.e., biocompatibility, flexibility, high water retention and good cell adhesion, BC is currently commercialized as a wound dressing material for tissue regeneration [1-3]. Due to its moldability and good mechanical properties, comparable to that of thin blood vessels [4], BC may be used in coronary surgery as artificial vessels. Recent works has 
shown that surface modified BC can also be a valuable material for other applications, such as food packaging [5-7], ultrafiltration [8] or heavy metal ion removal [9]. Surface functionalization of BC membranes for increased hydrophobicity is needed for these applications, for example for moisture resistant packaging films with good barrier against water penetration [5].

Several attempts to increase BC surface hydrophobicity have been reported [5,10-15]. Dried BC membranes were immersed in the colloidal suspension of flavonoid silymarin-zein nanoparticles and showed increased hydrophobicity and antimicrobial activity, being studied for food packaging [5]. Dried BC membranes were also functionalized by 3-aminopropyl triethoxysilane (APS) in hexane, and showed enhanced cell attachment and proliferation, being studied for wound dressing application [10]. Wet BC membranes were modified by APS in ethanol at room temperature, and it showed effective antibacterial and antifungal activities against Escherichia coli, Staphylococcus aureus, Bacillus subtilis and Candida albican [11]. An extra-curing step at $110{ }^{\circ} \mathrm{C}$ was proposed for APS functionalized $\mathrm{BC}$ membranes to ensure the chemical grafting of bioactive moieties onto the surface of $\mathrm{BC}$ and to avoid the leaching of the biocidal agent [12].

$\mathrm{BC}$ was also surface functionalized for increasing the compatibility between hydrophilic BC and hydrophobic polymers, for the manufacture of bioplastics [13-16]. Thus, BC nanoribbons, released from the membrane by a wet mechanical process, were surface modified by organic acids with different length (acetic, hexanoic and dodecanoic acids) [13] or by acetylation using a solvent-free process [16]. Pristine BC membranes were also acetylated using a solvent-free process [14] or in toluene by solvent exchange [15].

Acetylation and grafting of aminoalkyl silanes are the most studied methods for compatibilization in polymer- $\mathrm{BC}$ composites or for improving the antimicrobial activity of bacterial cellulose. These treatments might be the choice in the case of $\mathrm{BC}$ membranes for food packaging too. BC is highly hydrophilic, similar to the cellulose fibers from plants and the functionalization of its surface is required for a better resistance to moisture, improved barrier properties and the preservation of these properties in contact with food. Although the physical and chemical modification of cellulosic films was carried out for distinct applications, the surface functionalization of $\mathrm{BC}$ for food packaging is still not studied in detail. The purpose of our work was to select a suitable treatment to increase the hydrophobicity of BC membranes for food packaging. To this aim, chemical grafting of BC under environmentally friendly conditions was carried out using different agents. Water or ethanol as "green" reaction medium and room or slightly higher temperature was chosen as eco-friendly conditions for these treatments. BC membranes were functionalized with two silanes, APS and vinyl-triethoxy silane (VS), by acylation and acrylation in water or ethanol/water mixture. Untreated and surface treated BC membranes were characterized by Fourier transform infrared (FTIR) spectroscopy, X-ray photoelectron spectroscopy (XPS) and contact angle to emphasize the surface functionalization. X-ray diffraction (XRD) was used to detect the possible changes in crystallinity or structure and thermo-gravimetric analysis (TGA) to assess the influence of these treatments on the thermal stability of BC. A thorough study was carried out to highlight the morphological changes using atomic force microscopy (AFM), Peak force-Quantitative nanomechanical mapping (PFQNM) and scanning electron microscopy (SEM).

\section{Materials and Methods}

\subsection{Materials}

BC membranes were used as received from the National Institute for Chemical Pharmaceutical Research and Development (Bucharest, Romania). Reagent grade 3-aminopropyl triethoxy silane $(99 \%)$, vinyl-triethoxy silane ( $\geq 97 \%)$ and acrylic acid $(99 \%)$ were purchased from Sigma-Aldrich (St. Louis, MO, USA). Glacial acetic acid, acetic anhydride ( $\geq 98 \%)$, sulfuric acid $(99 \%)$, and ethanol were procured from Chimreactiv (Bucharest, Romania). Poly(3-hydroxybutyrate-co-3-hydroxyvalerate) copolymer (PHBV) with $2 \mathrm{wt}$.\% hydroxyvalerate was purchased from Goodfellow (Cambridge Limited, Cambridge, UK). All the reagents were used without further purification. 


\subsection{Surface Treatment of $B C$ Membranes}

Silane grafting was carried out using $6 \mathrm{wt} . \%$ APS or VS in an ethanol/water (90/10) mixture. The BC membranes were placed in the silane (APS or VS) solutions and gently stirred for $3 \mathrm{~h}$ in closed recipients at room temperature, then, they were placed in an oven and cured for $1 \mathrm{~h}$ at $120^{\circ} \mathrm{C}$. These APS and VS treated BC membranes (denoted as BC-APS and BC-VS, respectively) were washed several times with a mixture of ethanol and water to remove the un-reacted silanes. A $5 \mathrm{wt} . \%$ acrylic acid in water solution was used for the treatment: the $\mathrm{BC}$ membrane was left to soak in this solution for $24 \mathrm{~h}$ at room temperature and then heated for $1.5 \mathrm{~h}$ at $60^{\circ} \mathrm{C}$. Acetylation of $\mathrm{BC}$ membranes was carried out with (75 wt.\%) glacial acetic acid and (8 wt.\%) acetic anhydride, using sulphuric acid as a catalyst, at room temperature for $60 \mathrm{~min}$ under stirring. Acrylated and acetylated BC membranes were thoroughly washed with distilled water and were denoted as BC-AA and BC-Ac, respectively. All the treated $\mathrm{BC}$ membranes were dried in a vacuum oven for $24 \mathrm{~h}$ at $70{ }^{\circ} \mathrm{C}$, resulting dried surface treated $\mathrm{BC}$ membranes.

BC-PHBV membranes were prepared by the immersion of untreated and surface treated BC membranes in a chloroform solution of PHBV copolymer (1 wt.\%). Thereafter they were dried at room temperature for $48 \mathrm{~h}$.

\subsection{Characterization of $B C$ Membranes}

\subsubsection{AFM Investigation}

The surface morphology of treated and untreated $\mathrm{BC}$ membranes was investigated by atomic force microscopy, PF QNM mode, using a Bruker MultiMode 8 instrument (Santa Barbara, CA, USA). AFM images were captured in air at room temperature with a scan angle of $90^{\circ}$ and a scanning rate from 0.6 to $0.9 \mathrm{~Hz}$. A silicon tip with a spring constant of $40 \mathrm{~N} / \mathrm{m}$ and a resonant frequency of $300 \mathrm{kHz}$ was used for the measurements.

\subsubsection{Scanning Electron Microscopy}

SEM images of $B C$ membranes were obtained with a scanning electron microscope FEI Quanta Inspect FEG (FEI, Hillsboro, OR, USA) at an accelerating voltage of $30 \mathrm{kV}$ with a resolution of $1.2 \mathrm{~nm}$. $\mathrm{BC}$ membranes were fixed on adhesive tapes and sputter-coated with gold for $30 \mathrm{~s}$ before examination.

SEM images of BC-PHBV nanocomposites were captured with an environmental scanning electron microscope FEI Quanta 200, with tungsten electron source, at an accelerating voltage of $25 \mathrm{kV}$. All the nanocomposites were sputter-coated with gold for $30 \mathrm{~s}$ before examination.

\subsubsection{Contact Angle (CA) Measurements}

CA measurements were carried out using a CAM 200 (Biolin Scientific, Gothenburg, Sweden,) equipped with a high-resolution camera (Basler A602f) and an auto-dispenser, at room temperature and ambient humidity. The CA value was measured 1-2 s after the drop contacted the surface of the membrane. Five drops of deionized water were dispensed on each sample and the reported CA was an average of five values. The images of the droplets were acquired with the high-resolution camera using CAM software.

\subsubsection{XRD Analysis}

The crystalline structure of $\mathrm{BC}$ before and after treatments was characterized by XRD using a Dron-UM diffractometer (horizontal goniometer, Bragg-Brentano geometry, (Burevestnik R\&D Company, St. Petersburg, Russia) with Co K $\alpha$ radiation (wavelength $\lambda=1.79021 \AA$ ) at $2 \theta$ values from $4^{\circ}$ to $36^{\circ}$, with a scanning rate of $0.01^{\circ} / \mathrm{s}$. Samples were analyzed in reflection mode. The degree of 
crystallinity $(C I)$ was calculated as the ratio between the area under the crystalline peaks $\left(A_{c r}\right)$ and the total area, under the crystalline peaks and amorphous halo $\left(A_{a m}\right)$ :

$$
C I(\%)=\frac{A_{c r}}{A_{c r}+A_{a m}} \times 100
$$

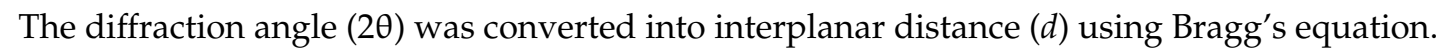

\subsubsection{FTIR Spectrosopy}

The FTIR-ATR analysis was carried out on a Tensor 37 spectrophotometer from Bruker (Billerica, MA, USA), with an ATR setup. Data were collected at room temperature from 4000 to $400 \mathrm{~cm}^{-1}$ with 16 scans per spectrum at a resolution of $4 \mathrm{~cm}^{-1}$. FTIR tests were conducted in duplicate.

\subsubsection{X-ray Photoelectron Spectroscopy}

XPS measurements were performed to understand better the chemical changes induced by the treatments on the surface of BC. A K-Alpha spectrometer (Thermo Scientific, Waltham, MA, USA) equipped with a monochromated $\mathrm{Al} \mathrm{K} \alpha$ source $(1486.6 \mathrm{eV})$ and operating in an ultrahigh vacuum (base pressure of $2 \times 10^{-9} \mathrm{mbar}$ ) was used for this purpose. Charging effects were compensated by a flood gun. The pass energy for the survey spectra was $200 \mathrm{eV}$, and for the high-resolution spectra it was $20 \mathrm{eV}$.

\subsubsection{Thermogravimetric Analysis}

TGA was performed on a SDT Q600 V20.9 (TA Instruments Inc., Lindon, UT, USA) using nitrogen as the purge gas at a flow rate of $100 \mathrm{~mL} / \mathrm{min}$. The samples $(5-7 \mathrm{mg})$ were packed in aluminum pans and tested from the ambient temperature to $700{ }^{\circ} \mathrm{C}$ at a heating rate of $10{ }^{\circ} \mathrm{C} / \mathrm{min}$.

\subsubsection{Dynamic Mechanical Analysis (DMA)}

The composite membranes were analyzed using a DMA Q800 (TA Instruments) operating in tensile mode. The specimens $(12.75 \mathrm{~mm} \times 7.0 \mathrm{~mm} \times 0.03 \mathrm{~mm})$ were heated from -45 to $160{ }^{\circ} \mathrm{C}$, at a heating rate of $3{ }^{\circ} \mathrm{C} / \mathrm{min}$, with a frequency of $1 \mathrm{~Hz}$, and $5 \mu \mathrm{m}$ amplitude. The experiments were performed on parallel specimens to ensure consistency.

\section{Results}

\subsection{Morphological Investigation by Atomic Force Microscopy and Scanning Electron Microscopy}

AFM images of BC membranes before and after the treatments are shown in Figure 1. BC has a loose network structure with entangled nanosized fibers and many holes. The different treatments induced different changes: a slightly more compact network was observed for BC-Ac and BC-AA and very compact structure for the $\mathrm{BC}$ treated with silanes. However, the width of the fibers was not modified by the treatments and it varied from 40 to $110 \mathrm{~nm}$, similar to other observations [17]. To get more insight into the surface properties of the membranes after the treatments, the surface roughness was analyzed using the topographic images of the membranes and AFM NanoScope software. Higher root mean square roughness (RRMS) values were determined for the untreated $B C$ membranes (RRMS $=103 \mathrm{~nm}$ ) compared to the treated ones, where RRMS was less than $50 \mathrm{~nm}$. This means that the fibers were brought closer together by the treatments, forming a smoother film with increased compactness, as also observed in the AFM images.

Surface functionalized BC membranes were also analyzed by SEM (Figure 2). SEM images emphasized some new aspects. Less single long nanofibers were detected on the surface of functionalized membranes, especially in the case of silane treated membranes where the nanofibers are grouped together and seem to be covered by a thin film. Higher magnitude SEM images (Figure 3) 
support this hypothesis, especially for AA and silanes treatments. Moreover, nanometric particles were observed on the surface of these samples. Cell impurities, which were not removed during the post-treatment of BC membranes, may join nanofibers as observed in Figure 2a (top left corner) for the untreated membrane but the large number of "impurities" observed on the surface of BC treated by AA or silanes is unusual. Besides cell debris these particles may come from cyclic or linear oligomers generated during the treatments. Indeed, previous works have shown that oligomers may be formed starting from silanes in different conditions [18,19].
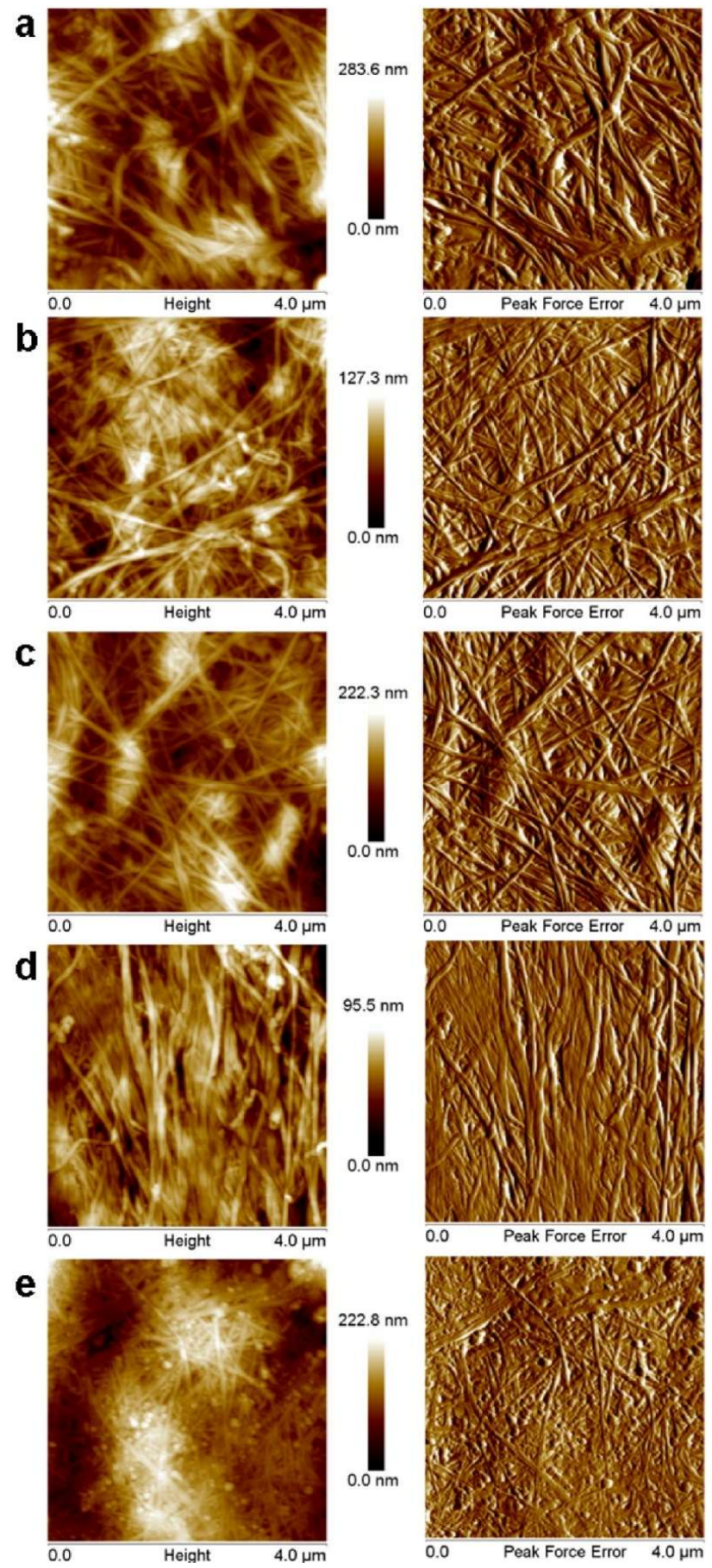

Figure 1. AFM topographic and peak force error images of BC (a), BC-Ac (b), BC-AA (c), BC-APS (d), BC-VS (e). 

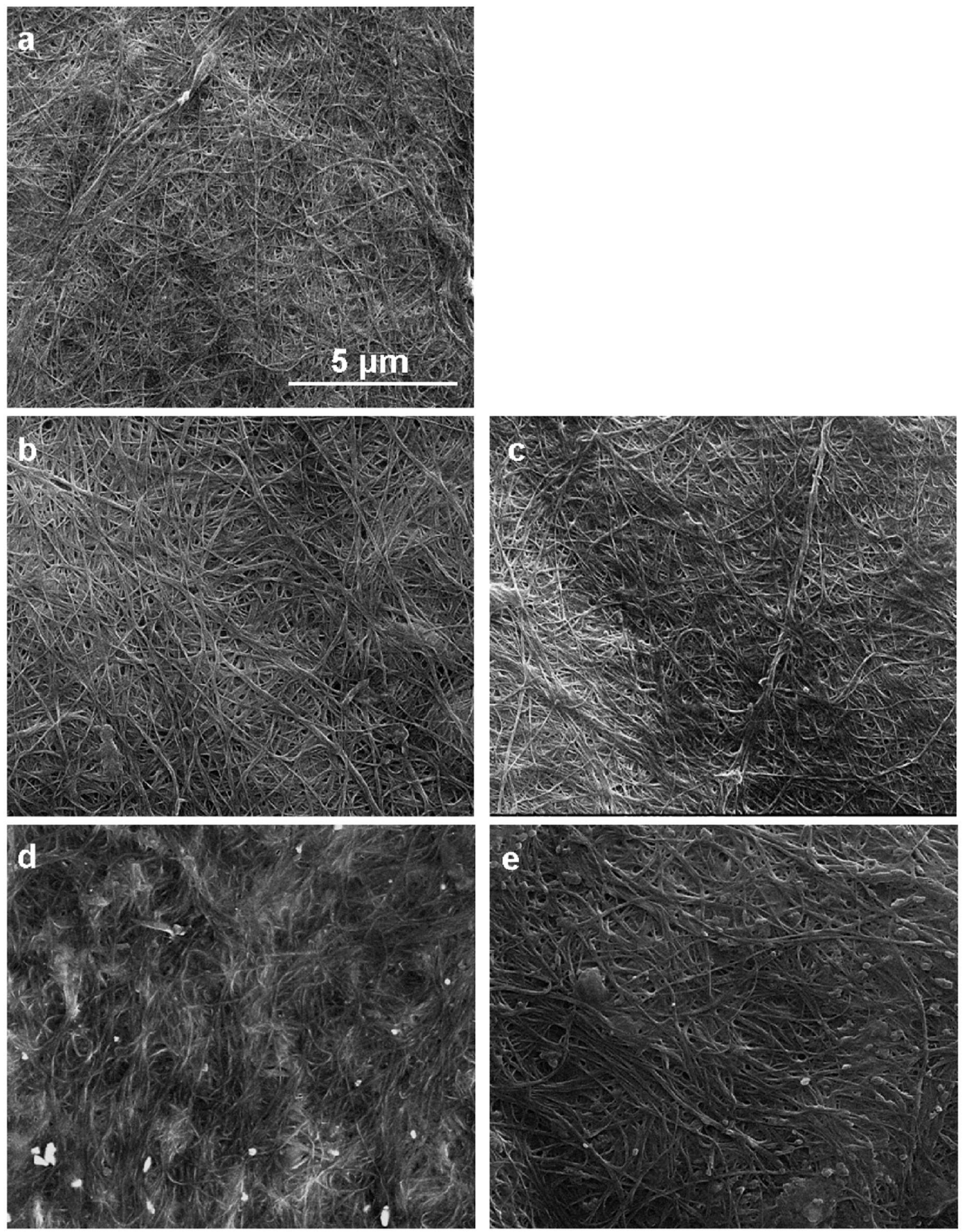

Figure 2. SEM images of BC (a), BC-Ac (b), BC-AA (c), BC-APS (d), BC-VS (e). 

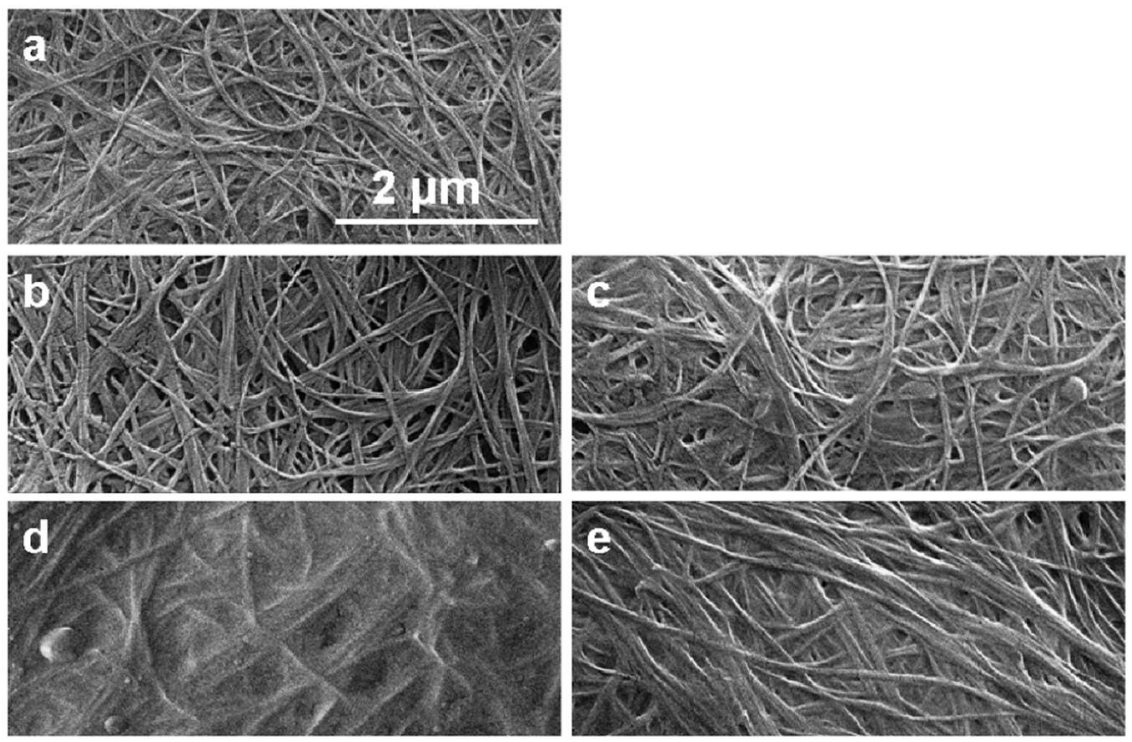

Figure 3. Detailed SEM images: BC (a), BC-Ac (b), BC-AA (c), BC-APS (d), BC-VS (e).

\subsection{Contact Angle Measurements}

The high hydrophilicity and porosity of $\mathrm{BC}$ membranes determine the absorption of water droplets during the CA measurements [20] and short time between the droplet release and image recording is necessary. It is expected that after treatments, the $\mathrm{BC}$ membranes will become more resistant to water and the droplets will remain for longer time on their surface. However, for comparison reasons, the same conditions were used for CA measurements in the case of treated membranes as for untreated ones i.e., the images were taken $1-2 \mathrm{~s}$ after the droplet reached the surface of the membrane. In these conditions, a CA value of about $30^{\circ}$ was obtained for the untreated BC membrane (Figure 4).

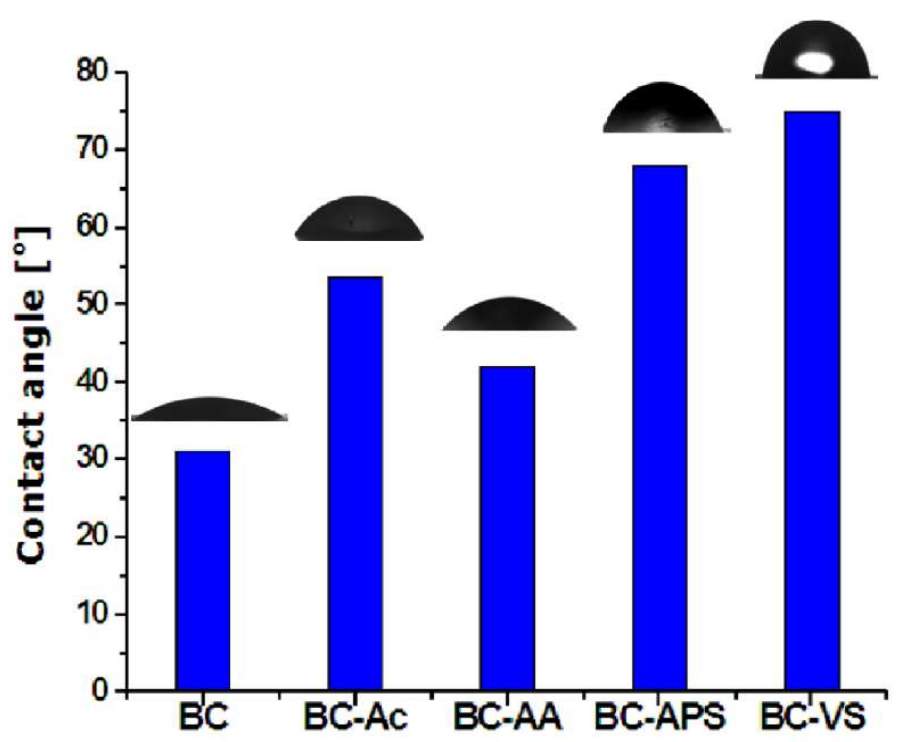

Figure 4. Contact angle values of untreated (BC) and treated membranes (BC-Ac, BC-AA, BC-APS and $\mathrm{BC}-\mathrm{VS})$; the images of the droplets for $\mathrm{CA}$ calculations were added for each type of membrane.

Much higher CA values were obtained for the functionalized BC membranes, $42^{\circ}$ for BC-AA, $54^{\circ}$ for $\mathrm{BC}-\mathrm{Ac}, 68^{\circ}$ for BC-APS and $75^{\circ}$ for BC-VS, corresponding to an enhanced hydrophobic character. 
The BC-AA showed a lower CA value due to the hydrophilic character of AA. Previous work has shown that AA was used to increase the hydrophilicity of polyester fabrics [21].

The images of the droplets for CA calculations were also given in Figure 4 for each type of $\mathrm{BC}$ membrane. Silane treatments were the most efficient in increasing the hydrophobicity of $\mathrm{BC}$ membranes; a twofold increase in CA value was obtained in the case of APS and a 2.5 times increase in the case of VS treatment.

\subsection{XRD Analysis}

XRD patterns of untreated and surface treated BC are shown in Figure 5. Bacterial cellulose contains both I $\alpha$ and I $\beta$ allomorphs, while I $\alpha$ is the dominant modification [22]. The Bragg's angles, interplanar distances $(d)$, and the degree of crystallinity are presented in Table 1 for the pristine membrane and for the treated ones (BC-Ac, BC-AA, BC-APS and BC-VS).

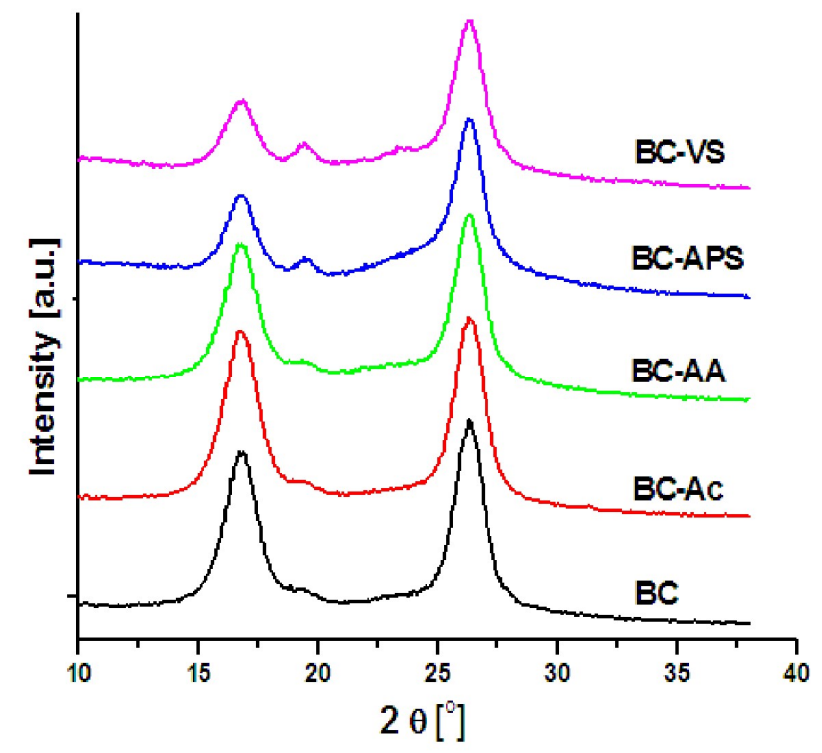

Figure 5. XRD patterns of the $2 \theta$ range of interest for untreated and surface treated BC.

Table 1. XRD data for untreated and treated BC.

\begin{tabular}{cccc}
\hline Samples & $\mathbf{2 \theta}{ }^{*}\left[{ }^{\circ}\right]$ & $\boldsymbol{d}_{\mathbf{1 0 0}} / \boldsymbol{d}_{\mathbf{0 1 0}} / \boldsymbol{d}_{\mathbf{1 1 2}} / \boldsymbol{d}_{\mathbf{1 1 0}}[\mathbf{n m}]$ & $\boldsymbol{C I}[\mathbf{\%}]$ \\
\hline BC & $16.8 / 19.4 / 23.4 / 26.3$ & $0.614 / 0.530 / 0.441 / 0.393$ & 84.1 \\
BC-Ac & $16.8 / 19.9 / 23.8 / 26.3$ & $0.615 / 0.510 / 0.435 / 0.393$ & 84.9 \\
BC-AA & $16.8 / 19.3 / 23.6 / 26.3$ & $0.615 / 0.534 / 0.438 / 0.393$ & 74.2 \\
BC-APS & $16.7 / 19.5 / 23.9 / 26.3$ & $0.615 / 0.529 / 0.432 / 0.393$ & 69.6 \\
BC-VS & $16.7 / 19.4 / 23.5 / 26.3$ & $0.615 / 0.530 / 0.439 / 0.393$ & 72.9 \\
\hline \multicolumn{4}{c}{ Note: * the wavelength of Co K $\alpha$ radiation used in the tests was $1.79021 \AA}$.
\end{tabular}

The four peaks characteristic to the crystallographic planes (100), (010), (112), and (110) in cellulose I were observed for untreated BC (Figure 5), and they were similar to previously reported data [22,23]. After treatments, the same crystalline structure was obtained, which is characteristic of cellulose I.

Although the position of the main peaks and the interplanar distances were roughly maintained after the treatments, some changes were observed in the intensity of the peaks. A decrease in the peaks' intensity was observed after the treatments with AA, APS and VS; this suggests a decrease of crystallinity $(C I)$. The most important decrease of crystallinity $(14 \%-17 \%)$ was induced by the silanes treatments (Table 1). One explanation for the $C I$ decrease after these treatments may be the decrease of the number of hydrogen bonds. It is known that the high degree of crystallinity of BC is determined 
by the regular arrangement of glucan chains favored by the high number of inter- and intra-molecular hydrogen bonds [24]. The treatments may disturb these bonds due to the esterification/silanization of the hydroxyl groups involved in hydrogen bonding. Previous work [23] has shown that the additives introduced in the fermentation media (during BC biosynthesis), which form chemical bonds with cellulose, had a high effect on $\mathrm{BC}$ crystallinity and led to a reduced crystallinity; those additives with no affinity to cellulose did not change the BC crystallinity. Therefore, it can be supposed that the treatments with AA, APS and VS, which led to the most important decrease of crystallinity (Table 1), were the most efficient treatments and caused the biggest changes in the chemical structure on $\mathrm{BC}$ surface. The influence of the treatments on the BC structure was also analyzed by FTIR-ATR.

\subsection{FTIR Analysis}

Figure 6 shows the FTIR spectra of the surface treated BC compared to that of pristine BC. All FTIR spectra were normalized using the $\mathrm{C}-\mathrm{H}$ stretching vibration from $2897 \mathrm{~cm}^{-1}$. The broad band from 3000 to $3500 \mathrm{~cm}^{-1}$ corresponds to the hydroxyl groups involved in the intra-chain and inter-chain hydrogen bonds within cellulose: $\mathrm{O} 3 \mathrm{H} \ldots \mathrm{O} 5$ intramolecular hydrogen bond at $3340 \mathrm{~cm}^{-1}, \mathrm{O} 2 \mathrm{H} \ldots \mathrm{O} 6$ and $\mathrm{O} 6 \mathrm{H} . . . \mathrm{O} 3$ intramolecular and intermolecular hydrogen bonds at $3410 \mathrm{~cm}^{-1}$ and $3294-3300 \mathrm{~cm}^{-1}$, respectively [25]. A decreased intensity of this band in the case of the treated $\mathrm{BC}$ membranes compared to the untreated one showed the involvement of $\mathrm{OH}$ groups in the grafting reactions and the decreased hydrophilicity, in agreement with the contact angle measurements.

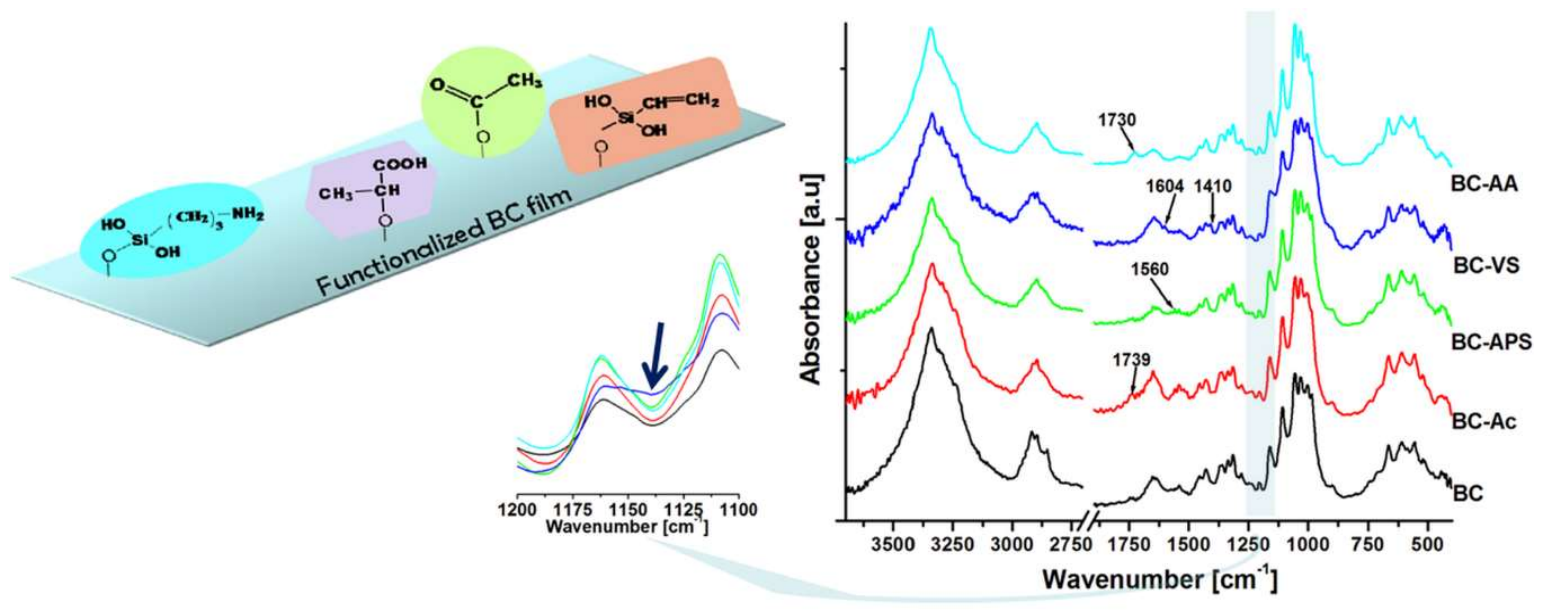

Figure 6. FTIR spectra of pristine and treated BC; detail-1200-1100 $\mathrm{cm}^{-1}$.

The broad peak at $1642-1654 \mathrm{~cm}^{-1}$ was ascribed to the $\mathrm{O}-\mathrm{H}$ bending of the absorbed water. Knowing that BC contains a small amount of cell debris, this peak is probably overlapped with the amide-stretching bands of proteins [26]. The band from 2850 to $2950 \mathrm{~cm}^{-1}$ is generally ascribed to asymmetric and symmetric $\mathrm{C}-\mathrm{H}$ stretching vibrations of methyl and methylene groups. Several peaks were noticed in this range for pristine BC $\left(2918,2895\right.$ and $\left.2852 \mathrm{~cm}^{-1}\right)$ but only the peak at $2895 \mathrm{~cm}^{-1}$ was more visible in the case of surface treated $\mathrm{BC}$, regardless the treatment. This suggests that the exocyclic $\mathrm{CH}_{2}$ group may be involved in physical or chemical interactions during the treatments [27]. However, no important changes were detected at 1428, 1370 and $1316 \mathrm{~cm}^{-1}$, which are related to the $\mathrm{C}-\mathrm{H}$ deformation.

Some differences between the FTIR spectra of surface treated BC and that of pristine BC may also be related to the efficiency of the treatments. New peaks, which are characteristic to the stretching vibration of $\mathrm{C}=\mathrm{O}$ group in esters, appeared in the FTIR spectra of BC-Ac and BC-AA at 1737 and $1730 \mathrm{~cm}^{-1}$, respectively. These groups have resulted from the reaction of the carboxylic acids with the $\mathrm{OH}$ groups of cellulose [28,29]. In addition, new small peaks were observed at 1604 and $790 \mathrm{~cm}^{-1}$ in 
$\mathrm{BC}$-VS; they arose from the $\mathrm{C}=\mathrm{C}$ stretching and show that the vinylsilane was coupled to the $\mathrm{BC}[30]$. Moreover, a shoulder which appeared at $1410 \mathrm{~cm}^{-1}$ in the spectrum of BC-VS due to the grafting with VS, may be ascribed to the vinyl group $\left(=\mathrm{CH}_{2}\right.$ scissors [31]). A new peak occurred in the spectrum of BC-APS at $1560 \mathrm{~cm}^{-1}$ and it was assigned to the bending of $-\mathrm{NH}_{2}$ [32] at the amino group. This is a proof of the successful bonding of APS to BC.

The characteristic bands of Si-O-Cellulose occur at $1100-1200 \mathrm{~cm}^{-1}$ and are covered by the strong peaks characteristic to the $\mathrm{C}-\mathrm{O}-\mathrm{C}$ vibration in cellulose [12]. Only in the FTIR spectrum of BC-VS, a shoulder was observed at around $1150 \mathrm{~cm}^{-1}$ (Figure 6-detail), that may be ascribed to the stretching of $\mathrm{Si}-\mathrm{O}-\mathrm{Si}$ or $\mathrm{Si}-\mathrm{O}-\mathrm{CH}_{3}$ bonds. Therefore, XPS analysis was performed to further demonstrate the presence of silanes on the surface of $\mathrm{BC}$.

\subsection{XPS Analysis}

XPS survey spectra of untreated and surface treated BC are shown in Figure 7.

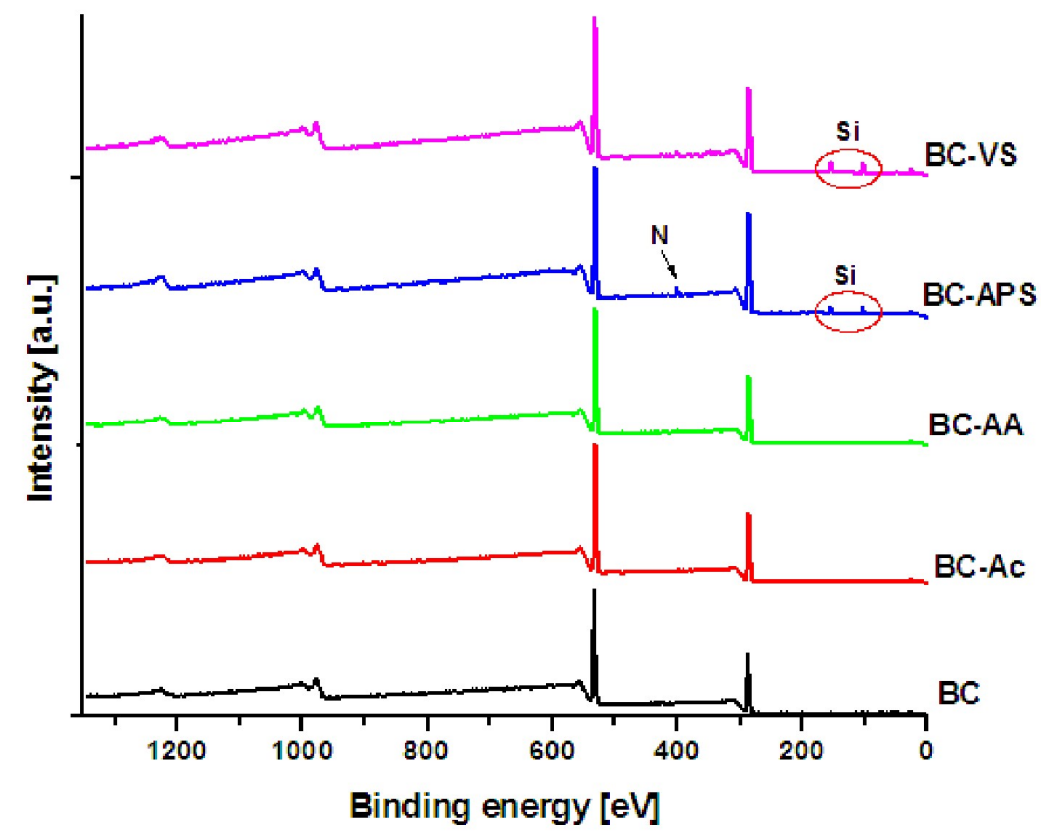

Figure 7. XPS survey spectra of treated BC.

The elemental compositions of the surface layer $(\sim 7 \mathrm{~nm})$ of $\mathrm{BC}$ are shown in Table 2 and confirm the presence of the $\mathrm{O}$ and $\mathrm{C}$ as main elements. The $\mathrm{O} / \mathrm{C}$ ratio in untreated $\mathrm{BC}(0.62)$ is different from the theoretical ratio for pure cellulose (0.83), probably because of the impurities and contamination; the $\mathrm{BC}$ membranes were used as received, after a simple wash and drying and may have been contaminated during the transport and storage. Similar O/C ratio (0.65) was reported for $\mathrm{BC}$ after TEMPO oxidation [33]. Besides O1s (532 eV) and C1s ( $285 \mathrm{eV})$ peaks, the spectrum of untreated BC contains traces of other elements, such as nitrogen (N) (Table 2), at $399 \mathrm{eV}$. Earlier studies have shown that traces of $\mathrm{N}$ may appear because of the residual proteins from BC-producing bacteria [10].

Similar O/C ratios were obtained for BC-Ac and BC-AA, 0.64 and 0.61 , respectively and almost no traces of other elements. With an equal proportion of $\mathrm{O}$ and $\mathrm{C}$ atoms, acetic acid should not influence the $\mathrm{O} / \mathrm{C}$ ratio of the original $\mathrm{BC}$ membrane and the slightly lower proportion of $\mathrm{O}$ atoms with respect to $C$ atoms $(2 / 3)$ in acrylic acid seems to have no significant influence on $O / C$ ratio. 
Table 2. Atomic concentrations of elements on the surface of untreated and treated BC acquired by XPS, survey scans.

\begin{tabular}{cccccc}
\hline Samples & O1s (\%) & C1s (\%) & Si2p (\%) & N1s (\%) & O/C \\
\hline BC & 37.7 & 61.0 & - & 1.2 & 0.62 \\
BC-Ac & 38.9 & 61.1 & - & - & 0.64 \\
BC-AA & 37.4 & 61.5 & - & 1.1 & 0.61 \\
BC-APS & 30.6 & 61.8 & 4.8 & 2.8 & 0.50 \\
BC-VS & 31.3 & 59.0 & 8.0 & 1.7 & 0.53 \\
\hline
\end{tabular}

New peaks were detected in the survey spectra of silanes treated samples (BC-APS and BC-VS) at 150 and $101 \mathrm{eV}$, which corresponds to Si2s and Si2p, respectively. This confirms the presence of silanes on the surface of $\mathrm{BC}$ and the effectiveness of these treatments. The lower atomic \% of $\mathrm{Si}$ in the case of BC-APS compared to BC-VS (4.8\% instead of $8.0 \%$ ) may come from different causes: the lower proportion of $\mathrm{Si}$ in the aminosilane formula with respect to vinylsilane, or different adsorption on the fiber surface and reactivity. Indeed, a lower degree of silanization on some natural fibers surface was reported for APS compared to other silanes [34]. In order to clarify this aspect, the degree of surface substitution (DSS) was determined using the atomic concentrations of Si determined by XPS, survey scans [35]. DSS represents the number of silyl groups/anhydroglucose unit and may quantify the grafting efficiency in the case of APS and VS treatments. The atomic concentrations of Si were converted in mass concentrations $(x)$ and replaced in the formula of DSS [36]:

$$
D S S=\frac{m G \times x}{m S i \times 100-m \operatorname{silan} \times x}
$$

where $m G$ is the molecular weight of one anhydroglucose unit, $m S i$ is the molecular weight of silicon and msilan the molecular weight of the grafted silane moieties. The mass concentrations of Si were $9.5 \%$ and $15.3 \%$ for BC-APS and BC-VS, respectively. The calculated DSS values, 0.9 and 1.7, indicate a high degree of silanization on the surface of $B C$ and explain the excellent increase of the contact angle observed in the case of BC-APS and BC-VS. The maximum theoretical value of DSS is 1.5 since only half of the three hydroxyl groups per glucose unit are accessible on the surface of $B C$ nanofibers [35]. For the VS treatment, DSS slightly exceeds this value, which suggests the occurrence of self-condensation as concurrent reaction to the grafting of $\mathrm{BC}$ and the presence of small amount of silane dimmers/oligomers on BC-VS surface. This is also sustained by the AFM and SEM images of BC-VS sample.

\subsection{TGA Analysis}

A good thermal stability of cellulose membranes is important for further impregnation or compounding with polymers, which have, usually, high melting point. Bacterial cellulose shows a good thermal stability, better than that of commercial microcrystalline cellulose [37], but the physical and chemical treatments may influence its thermal behavior $[5,37,38]$. The thermogravimetric curves for the treated and original BC are shown in Figure 8 and the main characteristic parameters are given in Table 3. All the samples had less than $5 \%$ weight loss up to $200{ }^{\circ} \mathrm{C}$, as showed in the inset of Figure 8 .

Table 3. TGA results for untreated and treated BC.

\begin{tabular}{cccc}
\hline Samples & $\boldsymbol{T}_{\boldsymbol{o n}}\left({ }^{\circ} \mathbf{C}\right)$ & $\boldsymbol{T}_{\boldsymbol{d}}\left({ }^{\circ} \mathbf{C}\right)$ & Residue at $\mathbf{7 0 0}{ }^{\circ} \mathbf{C}$ \\
\hline BC & 316.3 & 353.4 & 15.0 \\
BC-AC & 319.2 & 343.3 & 13.7 \\
BC-AA & 327.4 & 356.1 & 15.4 \\
BC-APS & 331.5 & 367.9 & 32.8 \\
BC-VS & 325.4 & 362.5 & 29.3 \\
\hline
\end{tabular}



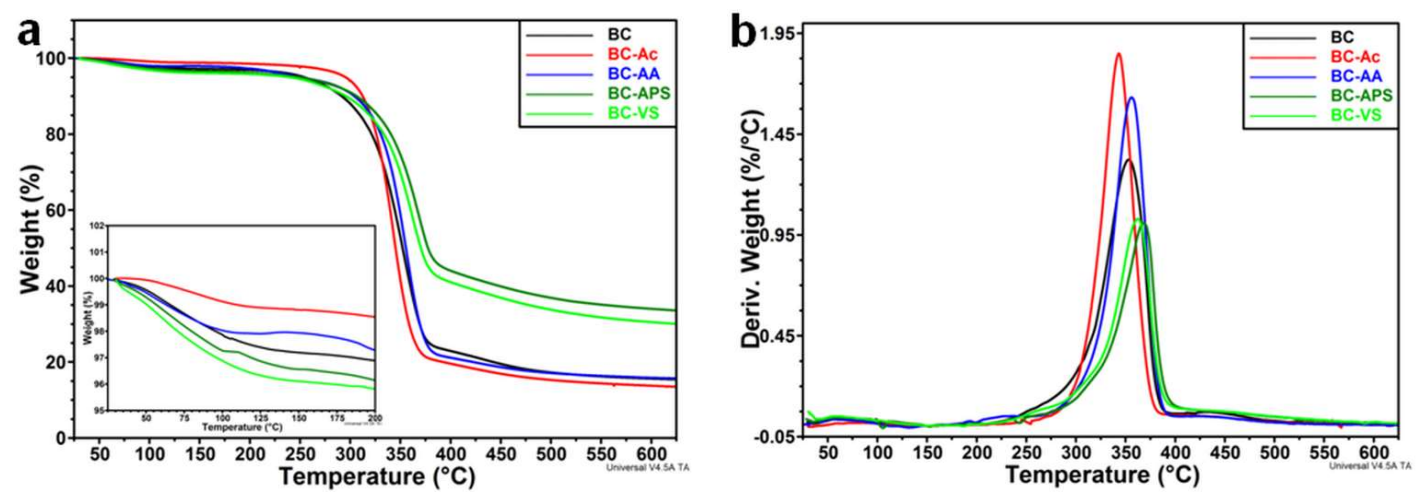

Figure 8. TGA (a) and DTG (b) curves of treated and original BC, inset-initial degradation step.

The DTG diagram of the original BC shows a three-step decomposition process: the first step was up to about $150{ }^{\circ} \mathrm{C}$ and was attributed to the release of free and bound water and the main degradation step including depolymerization, dehydration, and decomposition of the cyclic structures [37] was observed from about 200 to $400{ }^{\circ} \mathrm{C}$. In this main decomposition stage, about $75 \%$ of the mass of the original $\mathrm{BC}$ was lost. The shoulder observed on the right side of the main peak corresponds to the pyrolysis of cellulose [39]. The charred residue obtained from the original BC was 15\%.

Similar shaped DTG curves were obtained for the surface treated BC samples but with different characteristic temperatures and residue at $700{ }^{\circ} \mathrm{C}$ (Table 3). All the treated BC membranes showed higher onset thermal degradation temperature $\left(T_{o n}\right)$ than the original $\mathrm{BC} . T_{\text {on }}$ was defined as the intersection point between the lines drawn tangent to the two branches of the TGA curve. The highest increase was noted for BC-APS, with $15{ }^{\circ} \mathrm{C}, \mathrm{BC}$-AA and BC-VS showing an increase of $T_{\text {on }}$ with about $10^{\circ} \mathrm{C}$. This means that the applied treatments delayed the degradation of $\mathrm{BC}$ in the first stages. The maximum degradation temperature $\left(T_{d}\right)$ was higher for the $\mathrm{BC}$ treated with AA, APS and VS, BC-Ac showing a lower $T_{d}$ compared to untreated BC. The silane treatments determined the highest increase of thermal stability; they increased the $T_{d}$ value of the original $\mathrm{BC}$ with about $10^{\circ} \mathrm{C}$ and led to the highest residue. The increase of the residue at $700{ }^{\circ} \mathrm{C}$ with $100 \%$ for the BC-APS and BC-VS confirms the efficiency of the silane treatments and the chemical modification of $\mathrm{BC}$, which was also highlighted by FTIR and XPS results. Correlating the better thermal stability with the higher char residue obtained in the case of silanes treated $\mathrm{BC}$, it may be supposed that a charred layer rich in $\mathrm{Si}$ and $C$ was formed on the surface of $B C$ nanofibers protecting them from further degradation, as in the case of nanofibrillated cellulose treated with other silicon compounds [40].

It is worth mention that an onset degradation temperature of more than $320^{\circ} \mathrm{C}$ for surface treated $\mathrm{BC}$ is a very good thermal stability for an organic substrate, not achieved by other biopolymers.

\subsection{Caracterization of BC-PHBV Nanocomposites}

SEM micrographs of BC-PHBV nanocomposite membranes are given in Figure 9. All BC membranes were covered by a thin layer of polymer since the network of cellulose fibers was also observed. A uniform covering was noticed for BC-VS-PHBV membrane (Figure 9e) and places with more or less polymer were observed for all the others. This highlights the better distribution of the polymer in the case of VS treated BC probably because of a better polymer-fiber interface. Cellulose fibers bonded in strands, a couple of microns in width, were observed in the case of BC-APS-PHBV (Figure $9 \mathrm{~d}$-inset). These strands may be formed because of the crosslinking of grafted silanes. 

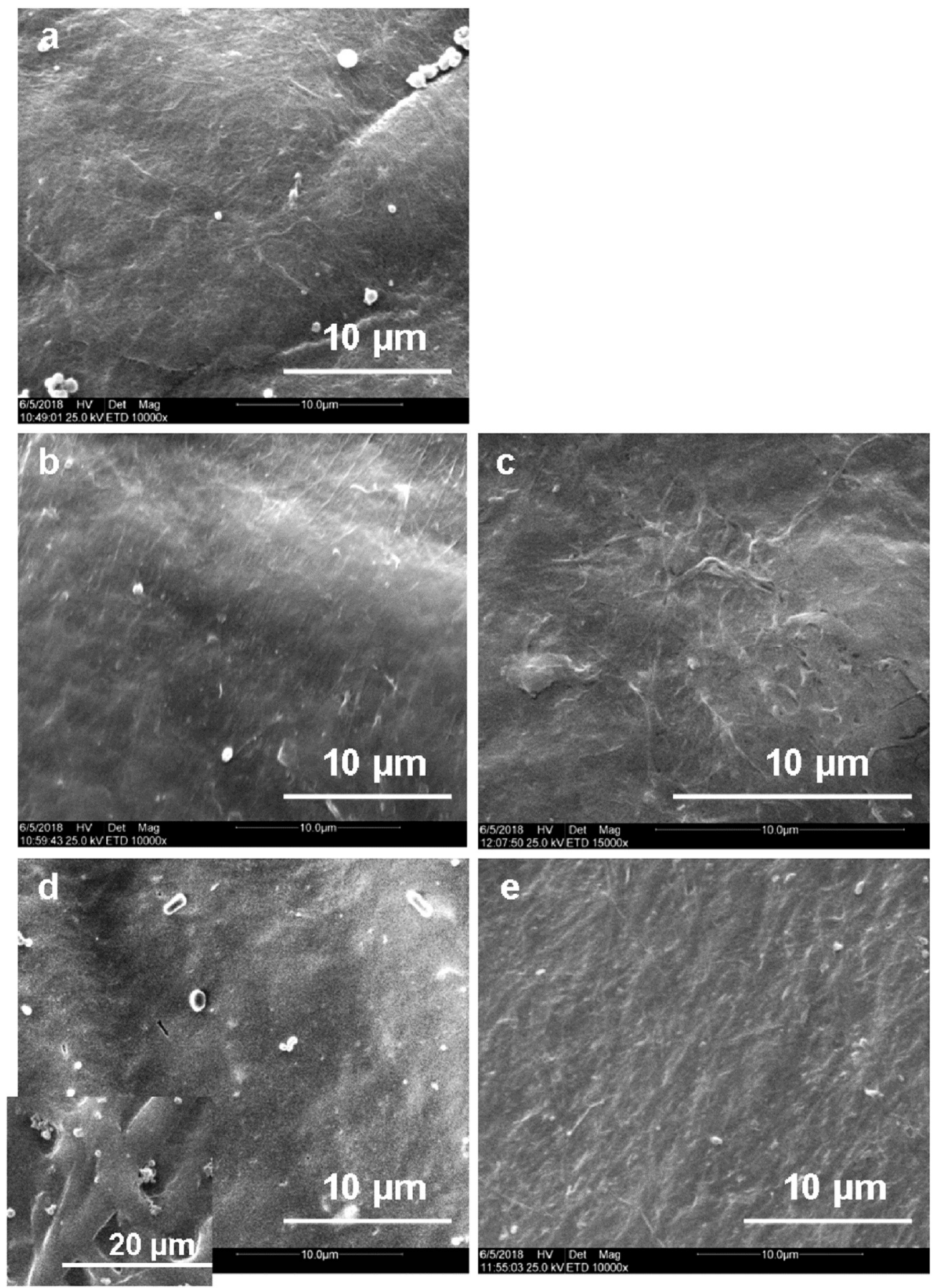

Figure 9. SEM micrographs of nanocomposites BC-PHBV (a), BC-Ac-PHBV (b), BC-AA-PHBV (c), BC-APS-PHBV with an inset showing the strands (d), BC-VS-PHBV (e).

The effectiveness of $B C$ surface functionalization was verified by measuring the mechanical properties of $\mathrm{BC}-\mathrm{PHBV}$ nanocomposite membranes. Figure 10 shows the loss modulus curves of pristine $\mathrm{BC}-\mathrm{PHBV}$ and treated $\mathrm{BC}-\mathrm{PHBV}$ samples. 


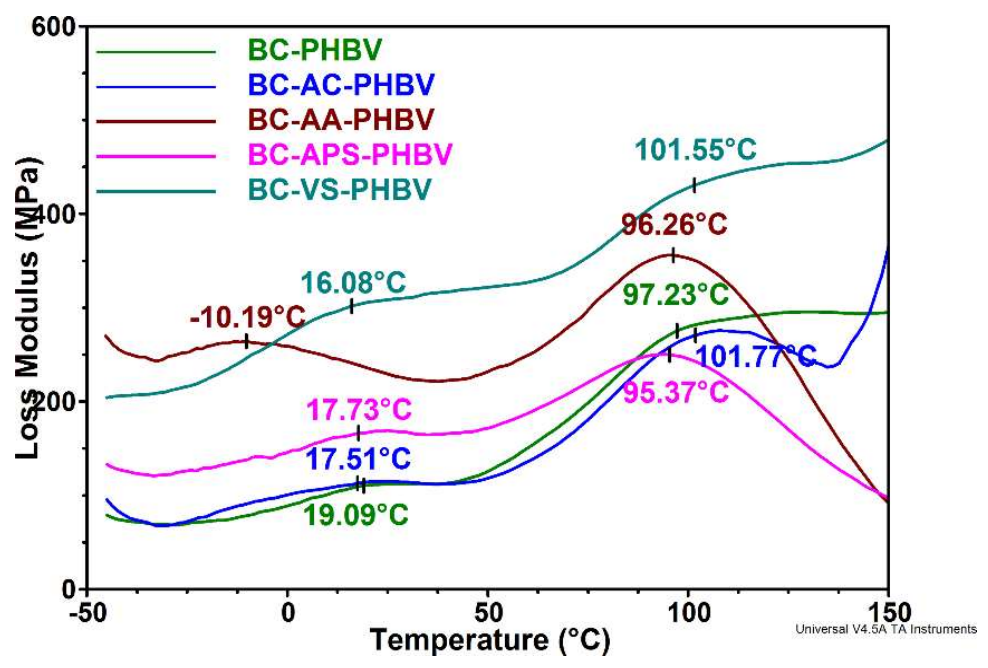

Figure 10. Loss modulus of different treated BC-PHBV nanocomposites.

Two relaxation peaks were noticed for PHBV, the first one in the low temperature range $\left(16-19{ }^{\circ} \mathrm{C}\right)$ and another one at higher temperature $\left(95-102^{\circ} \mathrm{C}\right)$. The low temperature peak corresponds to the glass transition $\left(T_{g}\right)$ of PHBV. The slight differences between pristine BC-PHBV and the nanocomposites with treated $\mathrm{BC}$ come from the different treatments on $\mathrm{BC}$. The broadening of this peak in the case of the nanocomposites with treated $\mathrm{BC}$ is also a result of the structural heterogeneity introduced by the surface treatment of membranes. A large shift of this peak towards lower temperature $\left(-10^{\circ} \mathrm{C}\right)$ was observed for BC-AA-PHBV nanocomposite showing increased flexibility, probably because of the presence of oligomeric products, also observed by SEM. The higher temperature peak corresponds to the crystal—crystal slippage occurring in PHBV in this temperature range [41]. No significant changes in the position of the second relaxation peak were observed in the case of surface treated BC-PHBV nanocomposites as compared to the pristine BC-PHBV membrane.

\section{Conclusions}

Different agents were used to modify the surface properties of $B C$, which is required by several applications. For example, BC membranes with increased hydrophobicity and moisture resistance may be used in food packaging after surface functionalization. For the selection of a suitable treatment, $\mathrm{BC}$ membranes were surface grafted using two different organosilanes, acetic anhydride and acrylic acid. FTIR and XPS analyses confirmed the efficiency of the surface treatments. All the treatments increased the compactness of the membranes and reduced the number and size of the holes. Still, this behavior was more pronounced in the case of silanized BC, conforming to the higher increase in hidrophobicity pointed out by contact angle measurements after the silane treatments. BC treated with silanes also showed a lower crystallinity, with about $15 \%$, compared to the pristine BC. This may be due to the grafting reaction and the reduction of hydrogen bonds. Improved flexibility was noticed for BC-AA-PHBV nanocomposite membrane and a more homogeneous covering with polymer in the case of BC-VS-PHBV membrane. Moreover, higher onset thermal degradation temperature was registered for all treated $\mathrm{BC}$ compared to the pristine $\mathrm{BC}$, the highest thermal stability being noticed for silanized membranes. Overall, the BC functionalization with silanes is an eco-friendly, effective method to obtain BC with increased hydrophobicity for food packaging applications.

Author Contributions: D.M.P. conceived and designed the experiments; A.N.F. established the methotdology; A.C.-BC biosynthesis; A.N.F., I.C. and A.R.G.-BC treatments; C.A.N.- thermal analysis; R.T. and E.A.-SEM investigations; C.M.D.-XPS analysis; V.P.-FTIR analysis; A.N.F. and D.M.P.-writing original draft; supervision-P.O.S. and D.M.P. 
Funding: This research was funded by the Ministry of Research and Innovation, CNCS-UEFISCDI, grant PN-III-P4-ID-PCE-2016-0431 (CELL-3D) within PNCDI III and grant PN 18.22.04.02/2018 (OXOBIOPOL) within Program NUCLEU.

Conflicts of Interest: The authors declare no conflict of interest.

\section{References}

1. Picheth, G.F.; Pirich, C.L.; Sierakowski, M.R.; Woehl, M.A.; Sakakibara, C.N.; de Souza, C.F.; Martin, A.A.; da Silva, R.; de Freitas, R.A. Bacterial cellulose in biomedical applications: A review. Int. J. Biol. Macromol. 2017, 104, 97-106. [CrossRef] [PubMed]

2. Dufresne, A. Nanocellulose: From Nature to High Performance Tailored Materials, 2nd ed.; Walter de Gruyter GmbH: Berlin, Germany, 2017; pp. 1-650. ISBN 3110478595, 9783110478594.

3. Stumpf, T.R.; Yang, X.; Zhan, J.; Cao, X. In situ and ex situ modifications of bacterial cellulose for applications in tissue engineering. Mater. Sci. Eng. C 2018, 82, 372-383. [CrossRef] [PubMed]

4. Klemm, D.; Schumann, D.; Udhardt, U.; Marsch, S. Bacterial synthesized cellulose-Artificial blood vessels for microsurgery. Prog. Polym. Sci. 2001, 26, 1561-1603. [CrossRef]

5. Tsai, Y.-H.; Yang, Y.-N.; Ho, Y.-C.; Tsai, M.-L.; Mi, F.-L. Drug release and antioxidant/antibacterial activities of silymarin-zein nanoparticle/bacterial cellulose nanofiber composite films. Carbohyd. Polym. 2018, 180, 286-296. [CrossRef] [PubMed]

6. Bayazidi, P.; Almasi, H.; Asl, A.K. Immobilization of lysozyme on bacterial cellulose nanofibers: Characteristics, antimicrobial activity and morphological properties. Int. J. Biol. Macromol. 2018, 107, 2544-2551. [CrossRef] [PubMed]

7. Padrao, J.; Gonçalves, S.; Silva, J.P.; Sencadas, V.; Lanceros-Mendez, S.; Pinheiro, A.C.; Vicente, A.A.; Rodrigues, L.R.; Dourado, F. Bacterial cellulose-lactoferrin as an antimicrobial edible packaging. Food Hydrocolloid. 2016, 58, 126-140. [CrossRef]

8. Jin, X.; Xiang, Z.; Liu, Q.; Chen, Y.; Lu, F. Polyethyleneimine-bacterial cellulose bioadsorbent for effective removal of copper and lead ions from aqueous solution. Bioresour. Technol. 2017, 244, 844-849. [CrossRef] [PubMed]

9. Hassan, E.; Hassan, M.; Abou-zeid, R.; Berglund, L.; Oksman, K. Use of bacterial cellulose and crosslinked cellulose nanofibers membranes for removal of oil from oil-in-water emulsions. Polymers 2017, 9, 388. [CrossRef]

10. Taokaew, S.; Phisalaphong, M.; Newby, B.Z. Modification of bacterial cellulose with organosilanes to improve attachment and spreading of human fibroblasts. Cellulose 2015, 22, 2311-2324. [CrossRef] [PubMed]

11. Shao, W.; Wu, J.; Liu, H.; Ye, S.; Jiang, L.; Liu, X. Novel bioactive surface functionalization of bacterial cellulose membrane. Carbohyd. Polym. 2017, 178, 270-276. [CrossRef] [PubMed]

12. Fernandes, S.C.M.; Sadocco, P.; Alonso-Varona, A.; Palomares, T.; Eceiza, A.; Silvestre, A.J.; Mondragon, I.; Freire, C.S.R. Bioinspired antimicrobial and biocompatible bacterial cellulose membranes obtained by surface functionalization with aminoalkyl groups. ACS Appl. Mater. Interfaces 2013, 5, 3290-3297. [CrossRef] [PubMed]

13. Lee, K.-Y.; Quero, F.; Blaker, J.J.; Hill, C.A.S.; Eichhorn, S.J.; Bismarck, A. Surface only modification of bacterial cellulose nanofibres with organic acids. Cellulose 2011, 18, 595-605. [CrossRef]

14. Hu, W.; Chen, S.; Xu, Q.; Wang, H. Solvent-free acetylation of bacterial cellulose under moderate conditions. Carbohyd. Polym. 2011, 83, 1575-1581. [CrossRef]

15. Ifuku, S.; Nogi, M.; Abe, K.; Handa, K.; Nakatsubo, F.; Yano, H. Surface modification of bacterial cellulose nanofibers for property enhancement of optically transparent composites: Dependence on acetyl-group DS. Biomacromolecules 2007, 8, 1973-1978. [CrossRef] [PubMed]

16. Avila Ramírez, J.A.; Gómez Hoyos, C.; Arroyo, S.; Cerrutti, P.; Foresti, M.L. Acetylation of bacterial cellulose catalyzed by citric acid: Use of reaction conditions for tailoring the esterification extent. Carbohyd. Polym. 2016, 153, 686-695. [CrossRef] [PubMed]

17. Lin, N.; Dufresne, A. Nanocellulose in biomedicine: Current status and future prospect. Eur. Polym. J. 2014, 59, 302-325. [CrossRef] 
18. Penso, I.; Cechinatto, E.A.; Machado, G.; Luvison, C.; Wanke, C.H.; Bianchi, O.; Soares, M.R.F. Preparation and characterization of polyhedral oligomeric silsesquioxane (POSS) using domestic microwave oven. J. Non-Cryst. Solids 2015, 428, 82-89. [CrossRef]

19. Panaitescu, D.M.; Gabor, R.A.; Nicolae, C.A.; Parau, A.C.; Vitelaru, C.; Raditoiu, V.; Chipara, M. Block copolymer elastomer with graphite filler: Effect of processing conditions and silane coupling agent on the composite properties. Polymers 2018, 10, 46. [CrossRef]

20. Thakur, V.K.; Thakur, M.K. Eco-Friendly Polymer Nanocomposites: Chemistry and Applications in Advanced Structured Materials; Springer: New Delhi, India, 2015; ISBN 978-81-322-2473-0.

21. Cireli, A.; Kutlu, B.; Mutlu, M. Surface modification of polyester and polyamide fabrics by low frequency plasma polymerization of acrylic acid. J. Appl. Polym. Sci. 2007, 104, 2318-2322. [CrossRef]

22. Bootten, T.J.; Harris, P.J.; Melton, L.D.; Newman, R.H. WAXS and 13C NMR study of Gluconoacetobacter xylinus cellulose in composites with tamarind xyloglucan. Carbohydr. Res. 2008, 343, 221-229. [CrossRef] [PubMed]

23. Dayal, M.S.; Catchmark, J.M. Mechanical and structural property analysis of bacterial cellulose composites. Carbohyd. Polym. 2016, 144, 447-453. [CrossRef] [PubMed]

24. Faria-Tischer, P.C.S.; Sierakowski, M.R.; Westfahl, H., Jr.; Tischer, C.A. Nanostructural reorganization of bacterial cellulose by ultrasonic treatment. Biomacromolecules 2010, 11, 1217-1224. [CrossRef] [PubMed]

25. Yue, Y.; Han, J.; Han, G.; Zhang, Q.; French, A.D.; Wu, Q. Characterization of cellulose I/II hybrid fibers isolated from energycane bagasse during the delignification process: Morphology, crystallinity and percentage estimation. Carbohyd. Polym. 2015, 133, 438-447. [CrossRef] [PubMed]

26. Ivanova, D.G.; Singh, B.R. Nondestructive FTIR monitoring of leaf senescence and elicitin-induced changes in plant leaves. Biopolymers 2003, 72, 79-85. [CrossRef] [PubMed]

27. Komar, V.P.; Zhbankov, R.G.; Makhsudov, Y.M.; Krylova, L.G.; Gal'braikh, L.S.; Rogovin, Z.A. Study of 3,6-anhydrocellulose and its derivatives by means of IR-spectroscopy. Polym. Sci. USSR 1966, 8, 2223-2229. [CrossRef]

28. Nishino, T.; Kotera, M.; Suetsugu, M.; Murakami, H.; Urushihara, Y. Acetylation of plant cellulose fiber in supercritical carbon dioxide. Polymer 2011, 52, 830-836. [CrossRef]

29. Kalia, S.; Kaith, B.S.; Sharma, S.; Bhardwaj, B. Mechanical properties of flax-g-poly(methyl acrylate) reinforced phenolic composites. Fiber. Polym. 2008, 9, 416-422. [CrossRef]

30. Sarifuddin, N.; Ismail, H. Applications of Kenaf-Lignocellulosic Fiber in Polymer Blends. In Lignocellulosic Polymer Composites; Thakur, V.K., Ed.; Scrivener Publishing LLC: Beverly, MA, USA, 2015; pp. 499-522.

31. Johnson, L.M.; Gao, L.; Shields, C.W., IV; Smith, M.; Efimenko, K.; Cushing, K.; Genzer, J.; López, G.P. Elastomeric microparticles for acoustic mediated bioseparations. J. Nanobiotechnol. 2013, 11, 22. [CrossRef] [PubMed]

32. Chen, Q.; Boothroyd, C.; Mcintosh Soutar, A.; Zeng, X.T. Sol-gel nanocoating on commercial $\mathrm{TiO}_{2}$ nanopowder using ultrasound. J. Sol-Gel Sci. Technol. 2010, 53, 115-120. [CrossRef]

33. Lai, C.; Sheng, L.; Liao, S.; Xia, T.; Zhang, Z. Surface characterization of TEMPO-oxidized bacterial cellulose. Surf. Interface Anal. 2013, 45, 1673-1679. [CrossRef]

34. Pothan, L.A.; Simon, F.; Spange, S.; Thomas, S. XPS Studies of Chemically Modified Banana Fibers. Biomacromolecules 2006, 7, 892-898. [CrossRef] [PubMed]

35. Goussé, C.; Chanzy, H.; Excoffier, G.; Soubeyrand, L.; Fleury, E. Stable suspensions of partially silylated cellulose whiskers dispersed in organic solvents. Polymer 2002, 43, 2645-2651. [CrossRef]

36. Andresen, M.; Johansson, L.-S.; Tanem, B.S.; Stenius, P. Properties and characterization of hydrophobized microfibrillated cellulose. Cellulose 2006, 13, 665-677. [CrossRef]

37. Amin, M.C.I.M.; Abadi, A.G.; Katas, H. Purification, characterization and comparative studies of spray-dried bacterial cellulose microparticles. Carbohydr. Polym. 2014, 99, 180-189. [CrossRef] [PubMed]

38. Panaitescu, D.M.; Frone, A.N.; Chiulan, I.; Casarica, A.; Nicolae, C.A.; Ghiurea, M.; Trusca, R.; Damian, C.M. Structural and morphological characterization of bacterial cellulose nano-reinforcements prepared by mechanical route. Mater. Des. 2016, 110, 790-801. [CrossRef]

39. Rosa, J.R.; da Silva, I.S.V.; de Lima, C.S.M.; Neto, W.P.F.; Silverio, H.A.; dos Santos, D.B.; da Silva Barud, H.; Ribeiro, S.J.L.; Pasquini, D. New biphasic mono-component composite material obtained by partial oxypropylation of bacterial cellulose. Cellulose 2014, 21, 1361-1368. [CrossRef] 
40. Fox, D.M.; Lee, J.; Zammarano, M.; Katsoulis, D.; Eldred, D.V.; Haverhals, L.M.; Trulove, P.C.; DeLong, H.C.; Gilman, J.W. Char-forming behavior of nanofibrillated cellulose treated with glycidyl phenyl POSS. Carbohydr. Polym. 2012, 88, 847-858. [CrossRef]

41. Wei, L.; Liang, S.; McDonald, A.G. Thermophysical properties and biodegradation behavior of green composites made from polyhydroxybutyrate and potato peel waste fermentation residue. Ind. Crops Prod. 2015, 69, 91-103. [CrossRef] 